\title{
Religion and Depression in Adolescence
}

\section{Jane Cooley Fruehwirth}

University of North Carolina

\section{Sriya lyer}

University of Cambridge

\section{Anwen Zhang}

London School of Economics and Political Science

\begin{abstract}
Depression is the leading cause of illness and disability in adolescence. Many studies show a correlation between religiosity and mental health, yet the question remains whether the relationship is causal. We exploit within-school variation in adolescents' peers to deal with selection into religiosity. We find robust effects of religiosity on depression that are stronger for the most depressed. These effects are not driven by the school social context; depression spreads among close friends rather than through broader peer groups that affect religiosity. Exploration of mechanisms suggests that religiosity buffers against stressors in ways in which school activities and friendships do not.
\end{abstract}

\section{Introduction}

Depression is the leading cause of illness and disability in adolescence worldwide. The World Health Organization lists mental health in adoles-

Fruehwirth thanks the British Academy and the Leverhulme Trust's Philip Leverhulme Prize for financial support and the Carolina Population Center and its National Institutes of Health Center grant (P2C HD050924) for general support. Iyer is grateful for the support provided by a Janeway Fellowship and the Cambridge-Institute for New Economic

Electronically published May 3, 2019

[ Journal of Political Economy, 2019, vol. 127, no. 3]

(C) 2019 by The University of Chicago. All rights reserved. $0022-3808 / 2019 / 12703-0005 \$ 10.00$ 
cence as a key issue that needs to be addressed (WHO 2014). In the United States, the incidence of a major depressive episode in adolescence has risen by more than a third over the past decade to 12.5 percent of adolescents as of 2015 (Center for Behavioral Health Statistics and Quality 2016). This is troubling for a number of reasons. First, depression during adolescence is correlated with a range of adverse outcomes, including lower academic achievement and noncognitive development (Cook, Peterson, and Sheldon 2009). Second, studies estimate that half of adults who suffer from mental health issues had symptoms that began in adolescence (WHO 2014). ${ }^{1}$ Third, the economic costs are substantial. Between 1996 and 2006, mental health expenditure rose rapidly from $\$ 35.2$ to $\$ 57.5$ billion and from the fifth to the third most costly medical condition in the United States (Agency for Healthcare Research and Quality 2014). ${ }^{2}$ In this paper, we examine the role of one important determinant of depression in adolescence-religiosity.

A contentious literature dating back to Freud in the early 1900s debates the role of religion in mental health and has been influential in the treatment of mental health problems (Levin 2010). ${ }^{3}$ Understanding the role of religion remains relevant today. More than eight in 10 people identify with a religious group worldwide (PewForum 2012). Sixty-five percent of Americans say religion plays an important part in their daily lives, and a majority of Americans claim religion could address most or all of

Thinking. We thank the editor James J. Heckman, three anonymous referees, Peter Arcidiacono, Daniel Chen, Donna Gilleskie, David Guilkey, Ju Hyun Kim, Brian McManus, Salvador Navarro, Alexei Onatski, Tiago Pires, Valentin Verdier, and seminar participants at University of North Carolina, Association for the Study of Religion, Economics, and Culture, Society of Labor Economists, Institute for Research on Poverty summer research workshop, University of North Carolina-Greensboro, Carolina Population Center, College of William and Mary, University of Western Ontario, Allied Social Science Association meetings, the Cambridge Public Health Network, North Carolina State, Lehigh, and InterAmerican Development Bank for helpful comments and Naifu Zhang for excellent research assistance. This research uses data from Add Health, a program project directed by Kathleen Mullan Harris and designed by J. Richard Udry, Peter S. Bearman, and Kathleen Mullan Harris at the University of North Carolina at Chapel Hill and funded by grant P01-HD31921 from the Eunice Kennedy Shriver National Institute of Child Health and Human Development, with cooperative funding from 23 other federal agencies and foundations. Special acknowledgment is due Ronald R. Rindfuss and Barbara Entwisle for assistance in the original design. Information on how to obtain the Add Health data files is available on the Add Health website (http://www.cpc.unc.edu/addhealth). No direct support was received from grant P01-HD31921 for this analysis. The contents of this paper are solely the responsibility of the authors and do not necessarily represent the official views of the funders. Data are provided as supplementary material online.

1 Williams, Holmbeck, and Greenley (2002) highlight adolescence as a key period of development that should be addressed because of its important consequences for mental health in adulthood.

${ }^{2}$ Langa et al. (2004) estimate a yearly cost of about $\$ 9$ billion for caregiving associated with depressive symptoms in elderly Americans, many of whom experienced depression in adolescence.

${ }^{3}$ Discussion of these issues features in Freud (1927) and his other writings, which examine religion and its effect on the human psyche. 
today's problems (Crabtree 2010; Newport 2014). Among adolescents, 31 percent of twelfth graders attend church on a weekly basis, and 28 percent report that religion plays a very important part in their lives (Child Trends Databank 2014a, 2014b).

Considerable scientific evidence suggests that religiosity is positively correlated with mental health, yet the meaning of this correlation remains a puzzle (Levin 2010; Ellison and Henderson 2011). We contribute to the debates about religion and mental health by first exploring whether the link between religiosity and depression can be interpreted as causal. Second, we combine insight from economics and social psychology to explore how religiosity affects depression, focusing particularly on the role of social context and stressors. The National Longitudinal Study of Adolescent to Adult Health in the United States, a nationally representative sample of adolescents in grades 7-12 in 1995, provides an excellent context for studying these questions, as it includes measures of depression, religiosity, and detailed information about the home, the school environment, and associated stressors.

The key challenge with establishing a causal effect of religiosity is the issue of selection into religiosity. In our context, it could be that religiosity simply proxies difficult-to-measure aspects of family background and that it is family background rather than religiosity that leads to lower depression. Further, it could be that people select into religiosity as a way of dealing with negative shocks to mental health (Ferraro and Kelley-Moore 2000). To deal with selection into religiosity based on individual unobservables, we focus on an alternative determinant of religiosity - school peers. We exploit arguably exogenous within-school, cross-cohort variation in peers to shift religiosity independently of the individual-level unobservable determinants of depression. Robustness checks help alleviate concerns about key confounders commonly understood in the peer effects literature: selection into peer groups and shared correlated unobservables among the adolescent and her peers (Manski 1993).

We then explore the determinants of the effect of religiosity on depression. The first channel we explore is the school social context, where we disentangle whether our estimated effect of religiosity is driven by an individual's religiosity or his or her school peers. Here, we benefit from observing friendship patterns in the data, which permit us to test a key theory that depression is spread among close friends rather than the broader peer group that we use to instrument for religiosity. We examine whether school clubs/sports participation and/or friendships substitute for religiosity. We also examine other key theories in the literature, including whether religiosity reduces exposure to or helps to buffer against stressful situations, and whether it improves self-esteem or coping skills. ${ }^{4}$ This pro-

\footnotetext{
${ }^{4}$ These theories are described in Ellison et al. (2001) and Ellison and Henderson (2011).
} 
vides important insight for policy and helps to support our claim of a causal effect of religiosity by illustrating plausible channels.

Our paper contributes methodologically to the literature in economics that addresses the difficult problem of disentangling a causal effect of religiosity (Iannaccone 1998; Hungerman 2011; Iyer 2016). The method we use is similar in spirit to those in Gruber (2005) and Mellor and Freeborn (2011), which use variation in religiosity at the county level to shift individual religiosity, relying on insight from the competition literature on how density of churches affects attendance. We build instead on the power of within-school peers to shift religiosity. ${ }^{5}$ What has received less attention in the economics of religion literature is whether the effect of religiosity derives through having a more religious social context or a direct effect of an individual's religiosity, which is implicitly confounded by most instrumenting strategies in the literature. ${ }^{6}$

A broad literature in psychology and sociology studies the link between religiosity, depression, and other indicators of mental health, but without establishing causality (Hackney and Sanders 2003; Levin 2010; Ellison and Henderson 2011). Recent overviews of the literature on religion and mental health support a need to better understand why religion improves mental health (Ellison et al. 2001; Nooney 2005). Chiswick and Mirtcheva (2013) is the only paper we are aware of that studies the effect of religiosity on mental health in youth and treats seriously the concerns about selection using matching methods, though the authors are not able to address selection on unobservables. ${ }^{7}$ Our study is also related to the growing literature in economics that recognizes the importance of noncognitive aspects of child development for determining outcomes (Heckman, Stixrud, and Urzua 2006; Cunha and Heckman 2008; Cunha, Heckman, and Schennach 2010).

We find that religiosity has sizable effects on depression in adolescence, which is understated by ordinary least squares (OLS) estimates that do not deal with selection into religiosity. For example, a one standard deviation increase in religiosity decreases the probability of being depressed by 11 percent. By comparison, increasing mother's education from no high school diploma to a high school diploma or more decreases the probability of being depressed by only about 5 percent. We find evidence suggesting that the peers (at the school-cohort level) that are associated with religiosity are different from the peers (self-reported friends)

\footnotetext{
${ }_{5}^{5}$ That peers affect religiosity is explored in Desmond, Morgan, and Kikuchi (2010) and Cheadle and Schwadel (2012).

${ }^{6}$ Even the most convincing identification strategies, such as Gruber and Hungerman (2008), do not take the additional step of separating these two channels.

7 Becker and Woessmann (2011) use a unique instrument for dealing with selection on unobservables, but in a very different context of nineteenth-century Prussia and focusing on the question of Protestantism and suicide.
} 
that are associated with depression, suggesting that our results are driven by individual religiosity rather than by the social context at the schoolcohort level. We further provide evidence on the types of stressors that religiosity helps to buffer against, providing useful insight for policy.

\section{Data}

We use data drawn from the restricted version of the National Longitudinal Study of Adolescent to Adult Health (Add Health). Add Health interviewed a representative sample of US adolescents in grades 7-12 (primarily aged 13-18) during the 1994/95 academic year. A short in-school survey was conducted for every student in the sampled schools. Following the in-school survey, a random sample of students also participated in an in-home survey, which provides more detailed information about the adolescent, including our primary variables of interest, religiosity and depression. ${ }^{8}$ This is supplemented with information about the child and his or her parent provided in the parent survey and is based primarily on self-reports.

Depression is measured on the Center for Epidemiological Studies Depression (CES-D) scale, one of the most common screening tests for depression and depressive disorder developed by Radloff (1977). It has been validated in a number of clinical trials. The CES-D scale consists of a list of symptoms, to each of which respondents report how often they experience the feeling. ${ }^{9}$ Responses are rated on a frequency scale ranging from $0=$ never or rarely to $3=$ most or all of the time. Response values are aggregated to create a point score, with higher scores indicating greater depressive symptoms. A score of 16 or above is considered to be indicative of moderate to severe depression (Radloff 1977). Appendix figure A1 shows the distribution of the depression scale. The distribution is skewed left with a long right tail; 24 percent show symptoms of depression (CES-D score $\geq 16$ ). While we primarily focus on the effect of religiosity on the CES-D scale, we also consider effects on the indicator of whether an adolescent is depressed by this definition, in order to get a better sense of magnitudes. We examine how sensitive our estimates are to the choice of threshold and to alternative scales in appendix A.3.

\footnotetext{
${ }^{8}$ On average, there are 330 students per school who respond to the in-home survey. While this is a fairly large sample, we will also consider whether measurement error caused by not sampling the whole school biases our estimates among the specification checks in online app. A.3. While Wave II also takes place in high school, we focus on Wave I because measurement error in the peer group becomes a larger issue in Wave II. That said, our results are similar, and even slightly larger, if we include Wave II.

${ }^{9}$ Table A1 lists the questions. The original CES-D scale lists 20 items, only 19 of which appear in Wave I of Add Health. Add Health substitutes the CES-D item "you felt life was not worth living" for two questions on sleeping and crying spells.
} 
The data provide information on four aspects of religiosity: frequency of church attendance, importance of religion, frequency of praying, and frequency of attending youth religious activities. Each aspect is assessed on a scale of $0-3$ or $0-4$. We use the aggregate of these four aspects as our main measure of religiosity. ${ }^{10}$ A limitation of the data is that only adolescents who report a religious affiliation were asked the more detailed religion-related questions. ${ }^{11}$ Therefore, we are able to study the effect of religiosity on mental health for only those who report having a religion, which is 85.9 percent of the sample. ${ }^{12}$ In principle, we expect this to understate the effect of religiosity, given that some people may be "religious" by the other measures but not report a religion. Sample means show that the nonaffiliated are statistically significantly more depressed, with a 12.3 average CES-D compared to 11.1 for the affiliated sample. We show robustness to including the nonreligious in appendix A.3.

Our identification strategy relies on defining a set of "similar" peers to which individuals are most likely to respond in choosing religiosity, based on students in the same school, grade, race, gender, and denomination, as discussed further in Section III. This requires categorizing race and denominations. We categorize race as white, black, Hispanic, or other. We group Christian faiths into Catholic, Liberal Protestant, Moderate Protestant, and Conservative Protestant. ${ }^{13}$ We drop non-Christian affiliations (4.7 percent of the sample), as they are arguably not largely substitutable across belief systems and no single affiliation has enough of a presence to be considered separately. ${ }^{14}$ Because peer religiosity is needed for identification, we also exclude those without a peer respondent from the main results, 14.9 percent of the sample. We show robustness to including nonChristians and those with missing peer groups in appendix A.3. The average peer group in our estimating sample has 11 students.

We control for a range of covariates in our specifications, taken primarily from the in-home and parent surveys: individual characteristics such as

${ }_{10}$ The details are in table A1. Principal component analysis based on polychoric correlations, which honor the ordinal nature of the measures, suggests that a single factor explains 77 percent of the variation. We find similar results if we use an extracted factor as our variable of interest rather than our index of religiosity; see app. A.3.

${ }^{11}$ Participants were asked "What is your religion?" and given a broad list of potential affiliations to choose from, as shown in table A2.

12 For the purposes of the social context calculations, individuals who report not having a religious affiliation are coded as having zero religiosity rather than missing religiosity, which we think provides a better approximation of the average religiosity of peers.

${ }^{13}$ The details of the categorization are summarized in table A2. The categorization is based on the Churches and Church Membership 1990 data, which collect county-level membership information on 133 Judeo-Christian church bodies in the United States. Add Health categorizes these church bodies as Jewish, Catholic, Black Baptist, other liberal, other moderate, and other conservative denominations in the Contextual Database.

${ }^{14}$ In the sample, 2.7 percent report being affiliated with an unspecified "other religion." The largest specified non-Christian religion, Jewish, is only 0.7 percent of the sample. 
age, sex, race, grade, denomination, physical development, and whether the respondent was interviewed during the school year session; parental background including whether mother or father was present, mother's education, and household income; and school fixed effects. Removing those with missing data on religiosity, depression, and covariates reduces the sample by about 3.8 percent.

Appendix table A3 describes how the final estimating sample compares to the original sample. The final sample has a marginally lower average CES-D (11.1 compared to 11.4), has marginally higher religiosity (8.6 compared to 8.5), and is marginally more affluent by a number of metrics in the table.

\section{Empirical Strategy}

Let $i$ index the individual student and $s$ the school. Adolescent $i$ 's mental health $\left(H_{i s}\right)$ is determined by religiosity $\left(R_{i s}\right)$, observable background characteristics $\left(\boldsymbol{X}_{i s}\right)$, and unobservable factors $\left(\varepsilon_{i s}\right)$, that is,

$$
H_{i s}=\alpha_{1} R_{i s}+\boldsymbol{X}_{i s}^{\prime} \boldsymbol{\alpha}_{2}+\alpha_{s}+\varepsilon_{i s},
$$

where $\alpha_{s}$ captures fixed school factors that might affect mental health. The key concern with identifying an effect of religiosity is unobservable individual characteristics that affect mental health and make an individual more likely to be religious, such that $\mathbb{E}\left(\varepsilon_{i s} \mid R_{i s}, \boldsymbol{X}_{i s}\right) \neq \mathbb{E}\left(\varepsilon_{i s} \mid \boldsymbol{X}_{i s}\right)$. For instance, religiosity may signal something about the home environment that affects mental health. Similarly, a shock, like the death of a friend or family member, could lead an individual to become more religious and also suffer from mental health issues. Reverse causality could also be a concern if individuals go to church as a way of dealing with poor mental health. It is thus ambiguous whether OLS estimates of equation (1) would over- or understate the effect of religiosity and depends on the type of selection that dominates.

To identify an effect of religiosity, we seek to isolate within-school variation in peers that shifts an individual's religiosity independently of $\varepsilon_{i s}$. Let the subscript $g(i) s$ denote the relevant peer group of student $i$ in school $s$, in a way that we will make specific below, and $\bar{R}_{g(i) s}$ denote the average of $i$ 's peers' religiosity, excluding $i$. Then the first-stage equation is simply

$$
R_{i s}=\beta_{1} \bar{R}_{g(i) s}+\boldsymbol{X}_{i s}^{\prime} \boldsymbol{\beta}_{2}+\beta_{s}+u_{i s},
$$

where $\beta_{s}$ denotes the school fixed effects and $u_{i s}$ the residual. For $\alpha_{1}$ to be identified, we need the following conditions to be satisfied:

Assumption A1. $\mathbb{E}\left(\varepsilon_{i s} \mid \bar{R}_{g(i) s}, \boldsymbol{X}_{i s}\right)=\mathbb{E}\left(\varepsilon_{i s} \mid \boldsymbol{X}_{i s}\right)$.

Assumption A2. $\mathbb{E}\left(R_{i s} \mid \bar{R}_{g(i) s}, \boldsymbol{X}_{i s}, S_{i}\right)$ is a nondegenerate function of $\bar{R}_{g(i) s}\left(\beta_{1} \neq 0\right)$, where $S_{i}$ is an indicator for the individual's school. 
An important question is how to define the peer group such that it meets the independence and relevance conditions. To begin with relevance (assumption A2), we first consider the friendship sorting patterns, with the intuition that adolescents who have a higher probability of being friends are more likely to influence each other. Table 1 contrasts the proportion of a student's schoolmates (col. 1) to the proportion of a student's friends (col. 2) who share a given characteristic. Consistent with evidence of homophily in McPherson, Smith-Lovin, and Cook (2001) and elsewhere, students are more likely to form friendships with other students of the same school, grade, race, and gender. An average adolescent shares the same school, grade, race, and gender with 8 percent of the students in the school but shares these characteristics with 40 percent of her friends. Homophily by religious affiliation is less pronounced but still present, with 3 percent of students in the school being of the same

TABLE 1

Friends SORTINg PATtern

\begin{tabular}{|c|c|c|c|}
\hline & $\begin{array}{l}\text { Proportion of } \\
\text { Students Sharing } \\
\text { Certain Characteris- } \\
\text { tics in the School } \\
\text { (1) }\end{array}$ & $\begin{array}{c}\text { Proportion of } \\
\text { Friends Sharing Cer- } \\
\text { tain Characteristics } \\
\text { among All Friends } \\
\text { (2) }\end{array}$ & $\begin{array}{c}\text { Difference }= \\
(1)-(2) \\
(3)\end{array}$ \\
\hline Of same school and grade & $\begin{array}{l}.277 \\
(.109)\end{array}$ & $\begin{array}{l}.713 \\
(.397)\end{array}$ & $\begin{array}{c}-.437 * * * * \\
(.005)\end{array}$ \\
\hline Of same school and race & $\begin{array}{l}.617 \\
(.305)\end{array}$ & $\begin{array}{l}.793 \\
(.375)\end{array}$ & $\begin{array}{c}-.176^{* * * *} \\
(.005)\end{array}$ \\
\hline Of same school and gender & $\begin{array}{l}.501 \\
(.040)\end{array}$ & $\begin{array}{l}.675 \\
.645 \\
(.393)\end{array}$ & $\begin{array}{l}-.144 * * * \\
(.005)\end{array}$ \\
\hline $\begin{array}{l}\text { Of same school and } \\
\text { denomination }\end{array}$ & $\begin{array}{l}.330 \\
(.224)\end{array}$ & $\begin{array}{l}.414 \\
(.442)\end{array}$ & $\begin{array}{c}-.084 * * * \\
(.005)\end{array}$ \\
\hline $\begin{array}{l}\text { Of same school, race, and } \\
\text { denomination }\end{array}$ & $\begin{array}{l}.219 \\
(.192)\end{array}$ & $\begin{array}{l}.352 \\
(.428)\end{array}$ & $\begin{array}{l}-.132 * * * \\
(.005)\end{array}$ \\
\hline $\begin{array}{l}\text { Of same school, grade, race, } \\
\text { and gender }\end{array}$ & $\begin{array}{l}.083 \\
(.058)\end{array}$ & $\begin{array}{l}.400 \\
(.423)\end{array}$ & $\begin{array}{c}-.317 * * * \\
(.005)\end{array}$ \\
\hline $\begin{array}{l}\text { Of same school, grade, race, } \\
\text { gender, and denomination }\end{array}$ & $\begin{array}{l}.030 \\
(.036)\end{array}$ & $\begin{array}{l}.182 \\
(.340)\end{array}$ & $\begin{array}{c}-.152^{* * * *} \\
(.004)\end{array}$ \\
\hline Observations & 6,342 & 6,342 & 6,342 \\
\hline
\end{tabular}

NoTE.-This table reports the proportions of students and friends who share the same characteristics. Col. 1 reports the share of students who share certain characteristics with the respondent in the school. Col. 2 reports the share of the respondent's friends who share certain characteristics with the respondent among all his or her friends. Col. 3 tests the difference between these two proportions using a $t$-test. Standard deviations (cols. 1 and 2) and standard errors (col. 3) are in parentheses.

* Statistically significant at the .10 level.

** Statistically significant at the .05 level.

*** Statistically significant at the .01 level. 
TABLE 2

Associations between Adolescents' Religiosity and the Religiosity of Their Friends And PeErs

\begin{tabular}{|c|c|c|c|}
\hline & \multicolumn{3}{|c|}{ DePEndent VARIAble $=$ Religiosity } \\
\hline & (1) & (2) & (3) \\
\hline Friends' religiosity & $\begin{array}{l}.126^{* * * *} \\
(.015)\end{array}$ & & \\
\hline Same-denomination friends' religiosity & & $\begin{array}{l}.164 * * * \\
(.022)\end{array}$ & \\
\hline Cross-denomination friends' religiosity & & $\begin{array}{l}.085^{* * * *} \\
(.015)\end{array}$ & \\
\hline Same-denomination peer religiosity ${ }^{\mathrm{a}}$ & & & $\begin{array}{l}.112 * * * \\
(.020)\end{array}$ \\
\hline Cross-denomination peer religiosity ${ }^{\mathrm{b}}$ & & & $\begin{array}{l}.017 \\
(.013)\end{array}$ \\
\hline
\end{tabular}

NoTE.-This table reports the estimates for regressions of adolescents' own religiosity on the religiosity of their friends or peers. All models control for covariates as in table A5. The number of observations is 12,945 in all models. Clustered standard errors at the school level are in parentheses. Not all observations have valid friends data or cross-denomination peers. Missing values for friends' religiosity or cross-denomination peer religiosity are coded as zeros, and dummy variables indicating these missing variables are included in the regressions where appropriate.

a This is calculated as the average religiosity of same-denomination peers in the same school and grade, of the same gender and race.

b This is calculated as the average religiosity of cross-denomination peers in the same school and grade, of the same gender and race.

* Statistically significant at the .10 level.

** Statistically significant at the .05 level.

*** Statistically significant at the .01 level.

school-grade-race-gender-denomination group compared to 18 percent of friends.

A second way we determine relevance is by estimating the first-stage equation (2) using different measures of peers' average religiosity. ${ }^{15}$ Table 2 , column 1 , shows that average friends' religiosity is positively correlated with own religiosity, and column 2 shows that this correlation is stronger for friends of the same denomination. ${ }^{16}$

Because these correlations are likely to be driven at least in part by sorting into friendships, we do not expect average friends' religiosity to be independent of the individual's unobservable type, violating the key independence assumption A1. Instead, we attempt to isolate plausibly random variation in peer religiosity by using variation in religiosity across cohorts

${ }^{15}$ While we control for selection into schools through school fixed effects, this regression has all the well-known identification problems defined in Manski (1993), but here we are attempting to establish correlation for our first-stage regression rather than causation.

${ }^{16}$ We control for missing friendships and replace missing values of friends' religiosity with zero. Sixty-five percent of the sample do not have friend's religiosity because this datum is available only for the subsample of students who are in the in-home survey, which is just a subset of any given adolescent's friends. 
within schools. Using the insights on sorting patterns and strong correlations with same-denomination friends to determine relevant cohorts, we define $\bar{R}_{g(i) s}$ as the average religiosity of peers in the same school-graderace-gender-denomination group. Column 3 of table 2 shows that peers of the same school, grade, race, gender, and denomination have statistically significant effects on religiosity (satisfying assumption A2) and stronger effects than same-school-grade-race-gender peers of other denominations, mirroring patterns we find in friendship correlations. ${ }^{17}$

In Section $V$ we discuss further evidence that independence is satisfied, considering two key challenges: (1) potential selection into having higherreligiosity peers of the same school-grade-race-gender-denomination and (2) the possibility that peer religiosity proxies for some shared unobservables that affect all students' religiosity and mental health. We further discuss mechanisms of this effect in Section VI, particularly considering whether the effects we find are driven by a student's own religiosity or by having peers who are more religious.

\section{Results}

\section{A. Baseline Results}

In table 3 we present the results for the OLS and instrumental variable (IV) estimation of the relationship between depression and religiosity. In all specifications, we control for individual characteristics, family background, and school fixed effects. We start with the OLS specification in column 1, which does not instrument for religiosity. These results suggest that religiosity decreases depression by -0.16 . Controlling for school fixed effects helps eliminate concerns about fixed factors at the school or community level that might affect both religiosity and mental health, but results that do not control for school fixed effects (not reported) are surprisingly similar (estimated coefficient is -0.15 ), suggesting that the correlations are not mediated by school-level unobservables.

Column 2 presents results when we instrument for religiosity using the average religiosity of same-school-grade-race-gender-denomination peers, and column 3 shows the first-stage results. First, note that peer religiosity is significant and positively predicts own religiosity, with an $F$-statistic of 30.44 , suggesting that we do not have a weak instrument problem. The estimated effect of religiosity on depression using our IV estimator is -0.70 , over four times as large as the OLS estimate of -0.16 , and it is statistically significant at the 5 percent level. In standardized terms, this indicates that a one standard deviation increase in religiosity leads to a 0.31 standard deviation reduction in the depression score. That the IV esti-

17 Table A4 shows that there is considerable variation in peer religiosity both within and across schools, grades, races, genders, and denominations. 
TABLE 3

Baseline Results for the Effect of Religiosity on Depression

\begin{tabular}{|c|c|c|c|c|c|c|}
\hline & \multicolumn{3}{|c|}{$\begin{array}{c}\text { DEPENDENT VARIABLE }= \\
\text { DEPRESSION }\end{array}$} & \multicolumn{3}{|c|}{$\begin{array}{c}\text { DEPENDENT VARIABLE }= \\
\text { DEPRESSED }\end{array}$} \\
\hline & $\begin{array}{l}\text { OLS } \\
(1)\end{array}$ & $\begin{array}{l}\text { IV } \\
(2)\end{array}$ & $\begin{array}{l}\text { First Stage } \\
\quad(3)\end{array}$ & $\begin{array}{l}\text { OLS } \\
(4)\end{array}$ & $\begin{array}{l}\text { IV } \\
(5)\end{array}$ & $\begin{array}{l}\text { IV Probit } \\
\text { (6) }\end{array}$ \\
\hline Religiosity & $\begin{array}{c}-.163 * * * \\
(.024)\end{array}$ & $\begin{array}{c}-.698 * * \\
(.289)\end{array}$ & & $\begin{array}{c}-.006^{* * * *} \\
(.001)\end{array}$ & $\begin{array}{c}-.034^{* *} \\
(.016)\end{array}$ & $\begin{array}{c}-.034 * * \\
(.016)\end{array}$ \\
\hline Peer religiosity & & & $\begin{array}{l}.112 * * * \\
(.020)\end{array}$ & & & \\
\hline Controls & Yes & Yes & Yes & Yes & Yes & Yes \\
\hline $\begin{array}{l}\text { School fixed effects } \\
F \text {-statistic }\end{array}$ & Yes & Yes & $\begin{array}{r}\text { Yes } \\
30.438\end{array}$ & Yes & Yes & Yes \\
\hline
\end{tabular}

NoTE.-This table reports the OLS and IV estimates of religiosity on the CES-D scale of depression and the probability of being depressed. The instrumental variable peer religiosity is calculated as the average religiosity of peers (excluding oneself) of the same school, grade, race, gender, and denomination. Cols. 1-5 report the coefficients, whereas col. 6 reports the marginal effects at the mean. Clustered standard errors at the school level are in parentheses. The F-statistic on the excluded instrument refers to the Wald version of the Kleibergen and Paap (2006) rk-statistic on the excluded instrumental variables for non-i.i.d. errors (Baum, Schaffer, and Stillman 2002). The number of observations is 12,945 in all models (31 observations are not used for identification in model 6 because of perfect prediction of school fixed effects). Estimates for control variables are omitted here but reported in table A5.

* Statistically significant at the .10 level.

** Statistically significant at the .05 level.

*** Statistically significant at the .01 level.

mates predict more negative effects of religiosity than OLS suggests there may be negative selection into religiosity; that is, more depressed adolescents participate in more religious activities, biasing OLS toward zero. One explanation for this selection is that adolescents may choose religion as a way of coping with depression or other difficult home circumstances that are correlated with depression. This is consistent with evidence in Ferraro and Kelley-Moore (2000), which shows that some health problems lead to increased religiosity. An alternative interpretation is that religiosity is measured with error, and thus the OLS results understate the effect relative to IV. An additional interpretation is that IV and OLS results may not be directly comparable if there are heterogeneous effects, as OLS estimates the average treatment effect and IV a weighted local average effect for those adolescents whose religiosity is affected by their peers. We return to consider heterogeneity in treatment effects in Section IV.B.

To get an idea of the magnitude of these effects, we consider an indicator of whether the adolescent is depressed as an alternative dependent variable. ${ }^{18}$ Columns 5 and 6 present IV results from the linear probability

${ }_{18}$ Recall that CES-D greater than or equal to 16 signals risk of moderate to severe depression (Radloff 1977). 


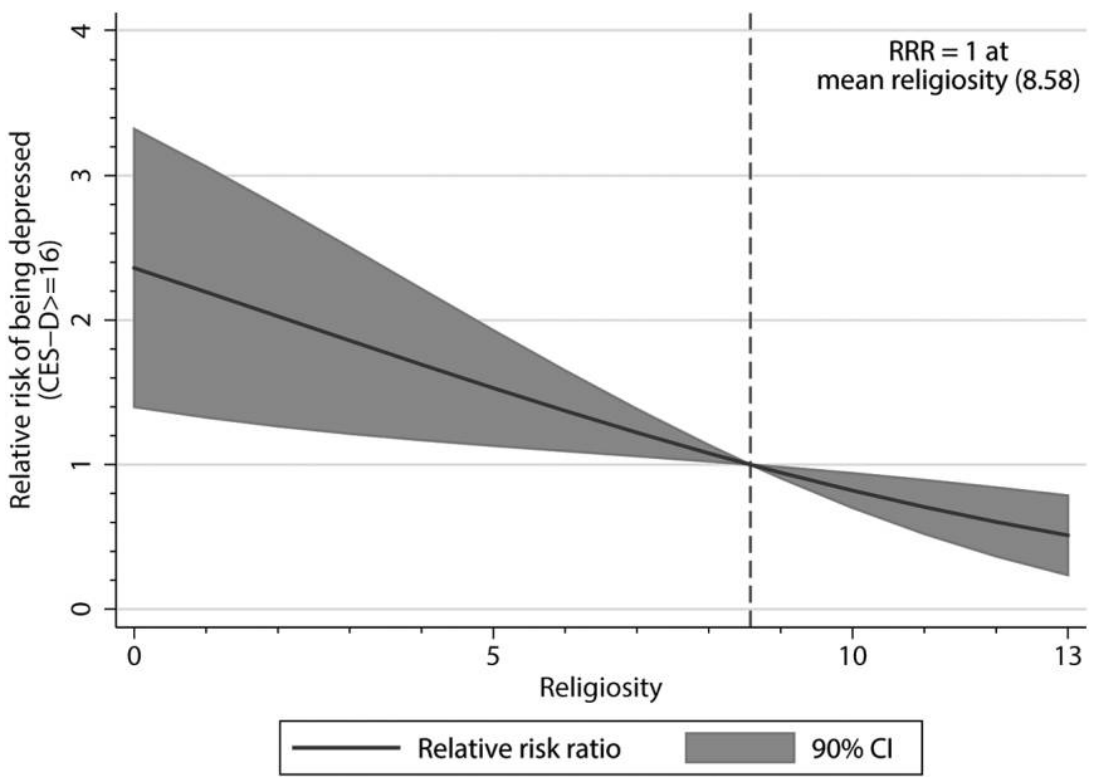

FIG. 1.-Predicted relative risk ratios (RRRs) at different levels of religiosity. Probabilities of being depressed (CES-D score $\geq 16$ ) are predicted for each level of religiosity from 0 to 13 on the basis of estimates from the IV probit model. RRRs are calculated as the ratios of the probability of being depressed for each level of religiosity to the probability of being depressed at mean religiosity (8.58). Color version available as an online enhancement.

model and IV probit model, respectively. ${ }^{19}$ The estimates are similar across the two models, suggesting that being one unit more religious decreases the probability of being depressed by 3 percent on average. A one standard deviation (or 3.3 units) increase in religiosity decreases the probability of being depressed by 11 percent. ${ }^{20}$ In terms of relative risks of being depressed, a one-unit (standard deviation) increase in religiosity leads to a relative risk ratio (RRR) of $0.87(0.62) .{ }^{21}$ Figure 1 presents the RRRs at each level of religiosity from 0 to 13 .

\section{B. Heterogeneity in Effects}

The effects of religiosity may vary depending on the individual's unobservable propensity for being depressed. This is particularly relevant given

${ }^{19}$ In the probit model, we control for school fixed effects using school dummies, though there is a concern about consistency for smaller schools.

${ }^{20}$ Table A7 shows that estimated effects of religiosity are similar at higher cutoffs for being depressed.

${ }_{21}$ RRRs are calculated as the probability of being depressed at a certain level of religiosity to that at the mean religiosity. Probabilities of being depressed are predicted from the IV probit model. 


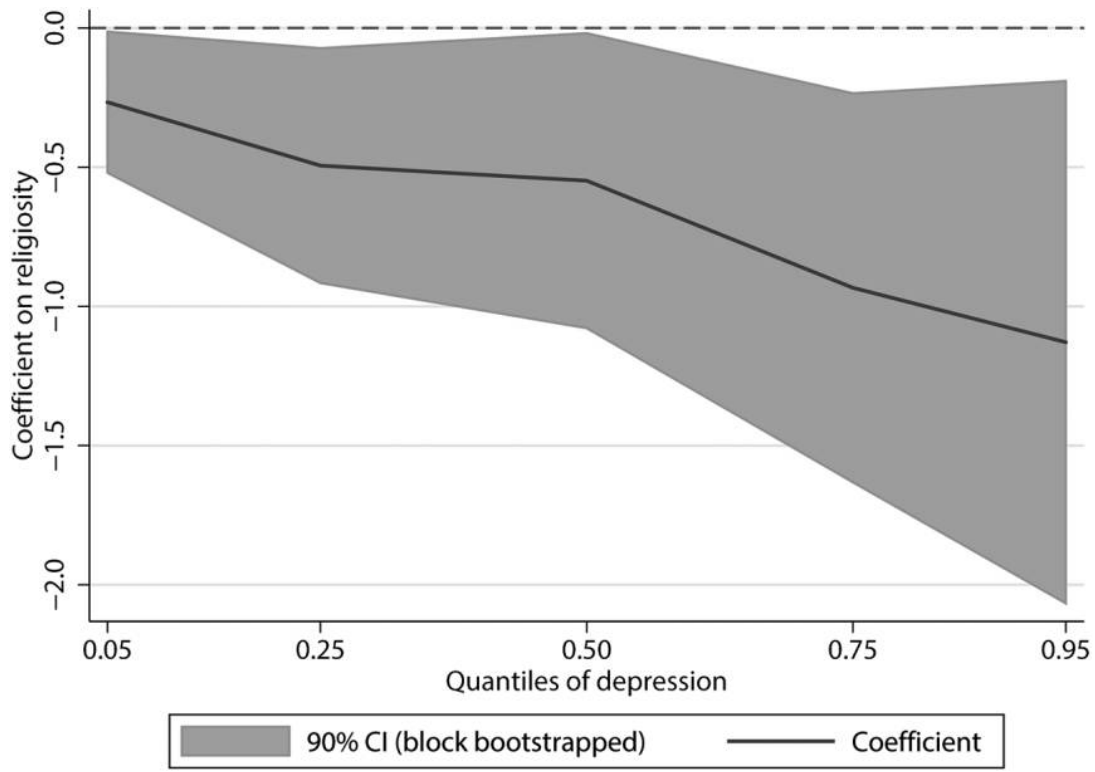

FIG. 2.- The effect of religiosity on different quantiles of the conditional depression distribution. Estimated quantile regression coefficients on religiosity and 90 percent confidence intervals are plotted for different quantiles of depression. Standard errors are obtained by block bootstrapping clustered at the school level with 500 replications. Estimation procedures are described in appendix A.3. Color version available as an online enhancement.

that psychotherapy, and particularly cognitive-based therapy (a primary method of treatment for depression in the United States), is generally accepted to be effective for mild to moderate depression and less so for more severely depressed individuals (Gloaguen et al. 1998). ${ }^{22}$ To explore how the effect of religiosity differs on the basis of severity of depression, we use a two-step control function approach, as described in detail in appendix A.1. Figure 2 shows that the effect of religiosity is higher for people who are conditionally more depressed: comparing the 0.05 quantile to the 0.95 quantile, we see that the estimated effect of religiosity increases from about -0.27 to -1.13 . That psychotherapy alone is less effective for more depressed individuals then offers an interesting contrast to the role of religiosity in these contexts.

We also explore nonlinear effects of religiosity on mental health based on how religious the individual is. We test this using a control function approach and try a number of different specifications of polynomials in

${ }^{22}$ There seems to be a broad consensus that more severely depressed individuals may need a combination of psychotherapy and antidepressant medication (March et al. 2007), as suggested by the guidelines posted by the National Institute for Mental Health. 
religiosity. We find little evidence of heterogeneity by degree of religiosity. ${ }^{23}$ Though we cannot completely rule it out, these specifications suggest that heterogeneity in the effects of religiosity may not be a primary reason that IV estimates are higher than OLS estimates.

\section{Robustness}

The key threats to identification are issues common in the peer effects literature: selection into peer groups and the presence of unobserved group-level effects. To clarify these threats in our context, it helps to divide the residual from the mental health equation (1) into a group-specific component $\left(\eta_{g(i) s}\right)$ and an individual-specific component $\left(\nu_{i s}\right)$, that is, $\varepsilon_{i s}=\eta_{g(i) s}+\nu_{i s}$. The group-specific component could be a direct effect of the peer group characteristics on mental health or other unobservable correlated factors. We discuss identification challenges associated with each of these components in turn.

\section{A. Selection into Peer Groups}

A primary channel in which $\mathbb{E}\left(\nu_{i s} \mid \bar{R}_{g(i) s}, \boldsymbol{X}_{i s}\right)=\mathbb{E}\left(\nu_{i s} \mid \boldsymbol{X}_{i s}\right)$ might be violated is through selection into peer groups based on unobservables that determine both mental health and religiosity. While school fixed effects control for selection into schools based on fixed characteristics at the school level, there may be other channels through which selection occurs. One example is the case in which students change their religious affiliation in response to their peers. While we believe this is not a concern in our context because of existing evidence that adolescents rarely deviate from the denomination of their parents (Smith and Denton 2005), in column 1 of table 4, we test robustness to replacing the adolescent's denomination with the parent's denomination both as a control variable and to define the relevant peer group for the instrument. ${ }^{24}$ Given that parents are arguably less likely than adolescents to choose a denomination on the basis of the adolescent's peers, this provides a useful test for ruling out potential endogenous denomination choices. Results are robust, though a bit noisier.

We next perform a series of robustness tests that relax our assumption of selection based only on fixed school factors. Column 2 shows that our

${ }^{23}$ One potential concern is whether this could be a result of the instrument we are using, in that peer religiosity does not shift over the full distribution of religiosity. To test this, we also estimate a quantile regression version of the first stage and find that peer religiosity has significant effects on all but the most religious ( 0.9 quantile of the conditional religiosity distribution), likely because of a ceiling effect. The estimated effects of peer religiosity are also fairly homogeneous across the conditional quantiles.

${ }^{24}$ Twenty-four percent of our sample have a denomination different from that of their parents, though this could in part be a result of observing only one parent's denomination. 


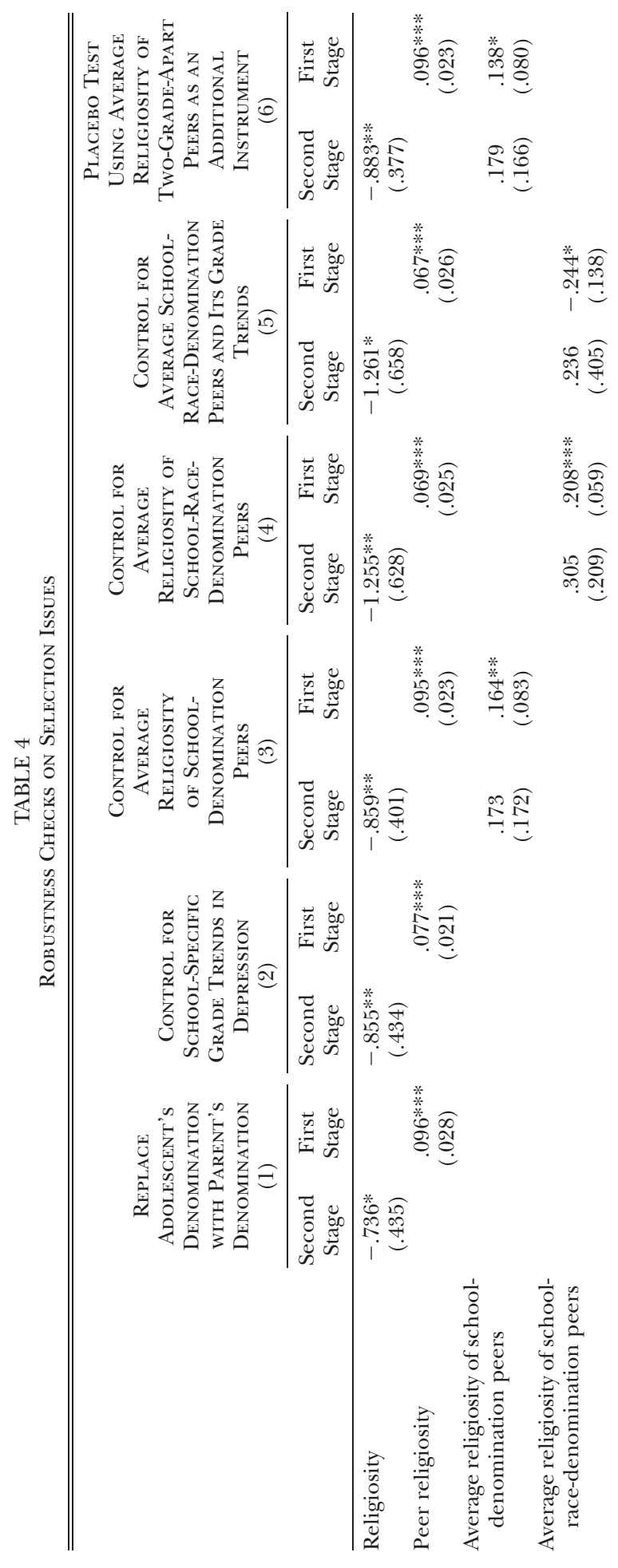

1192

This content downloaded from 130.209.115.082 on June 06, 2019 04:47:27 AM 


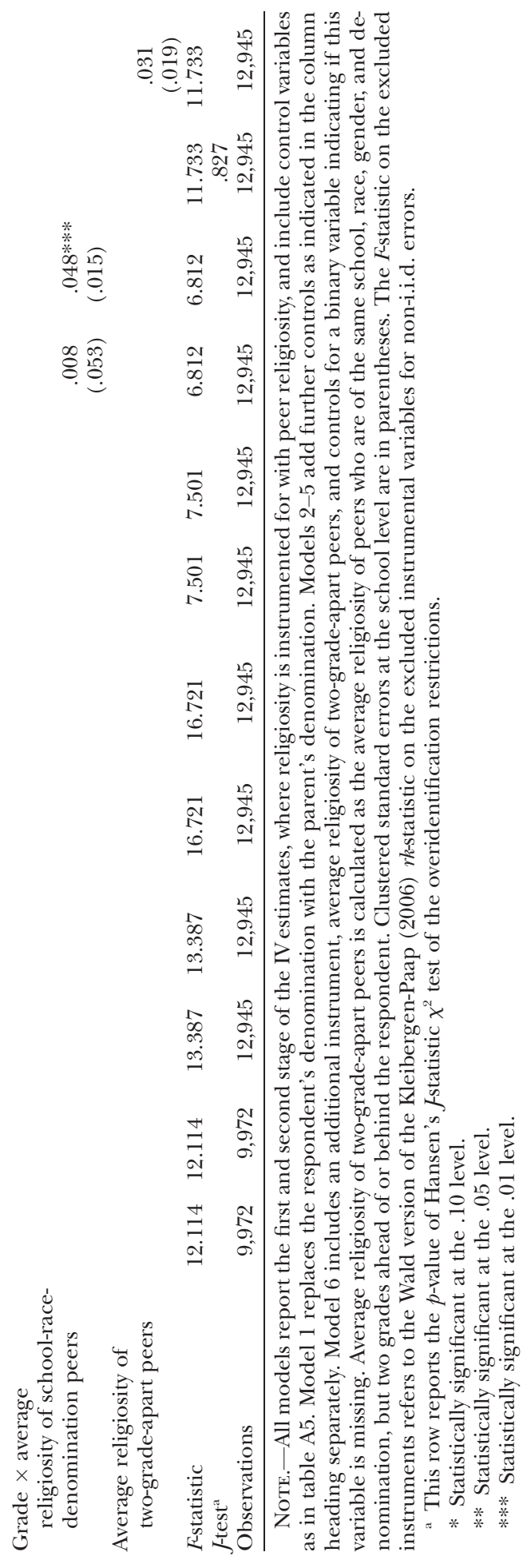

1193

This content downloaded from 130.209.115.082 on June 06, 2019 04:47:27 AM

All use subject to University of Chicago Press Terms and Conditions (http://www.journals.uchicago.edu/t-and-c). 
estimates are robust to controlling for selection based on school-specific trends. Column 3 shows robustness to controlling for selection into a neighborhood (and hence school) based on an influential local church by controlling for average religiosity of peers in the same school-denomination. While average school-denomination peer religiosity is a significant predictor of religiosity, our instrument remains significant. Most importantly, estimated effects of religiosity are robust. Interestingly, average schooldenomination religiosity does not have a statistically significant effect on depression, though point estimates are large. ${ }^{25}$ We then expand this in column 4 to control for average religiosity of same-race-denomination peers. We believe this to be an important additional check given the racial segregation of churches in the United States, even within denominations. We again see that while school-race-denomination average religiosity is a statistically significant predictor of religiosity, our instrument still has significant effects (though $F$-statistics are smaller at 7.5). Most importantly, estimated effects of religiosity are robust. Results are very similar in column 5 when we relax the assumption still further to allow for selection based on trends in average school-race-denomination religiosity. Limited information maximum likehood estimates, which are more robust to the potential concern about weak instruments in this setting, provide almost identical results. ${ }^{26}$

Finally, column 6 considers a placebo test that helps to rule out selection based on time-varying shocks. Without selection, we would expect that peers in the same time period but sufficiently far apart in school grades would not have an effect on each other's religiosity. We test whether this is the case considering peers that are two grades apart. The two-gradeapart peers have no effect on religiosity, and we pass the test of overidentifying restrictions, suggesting that they have no separate effect on depression either. $^{27}$

\section{B. Unobserved Group Effects}

The second central identification concern is whether there is some unobserved peer group-specific factor that violates $\mathbb{E}\left(\eta_{g(i) s} \mid \bar{R}_{g(i) s}, \boldsymbol{X}_{i s}\right)=$ $\mathbb{E}\left(\eta_{g(i) s} \mid \boldsymbol{X}_{i s}\right)$. An example would be some shock that hits the peer group causing all of the members to have lower religiosity and worse mental health. To be a threat to identification it would need to vary at the peer

\footnotetext{
${ }^{25}$ Results (not reported here) remain very similar when we control for grade trends in school-denomination average religiosity.

${ }^{26}$ We also try removing private schools from our analysis, out of the concern that selection on religiosity is more prominent in these schools. Our results are very similar.

${ }^{27}$ Comparable to other studies that claim random variation in peer composition within school, we confirm that peer religiosity does not significantly predict observable individual characteristics using balancing tests. See app. A.2.
} 
group level (so that it is not controlled by the school fixed effects) and be correlated with (but not determined by) peer religiosity. ${ }^{28}$ This can be clarified by rewriting equation (2) to solve for $\bar{R}_{g(i) s}$, which gives us

$$
\bar{R}_{g(i) s}=\frac{1}{1-\beta_{1}}\left[\overline{\boldsymbol{X}}_{g(i) s} \boldsymbol{\beta}_{2}+\beta_{s}+\bar{u}_{g(i) s}\right] .
$$

Assumption A1 then can be reinterpreted:

Assumption A1'.

$$
\begin{aligned}
\mathbb{E}\left(\varepsilon_{i s} \mid \overline{\boldsymbol{X}}_{g(i) s}, \bar{u}_{g(i) s}, \boldsymbol{X}_{i s}\right) & =\mathbb{E}\left(\eta_{g(i) s}+\nu_{i s} \mid \overline{\boldsymbol{X}}_{g(i) s}, \bar{u}_{g(i) s}, \boldsymbol{X}_{i s}\right) \\
& =\mathbb{E}\left(\eta_{g(i) s}+\nu_{i s} \mid \boldsymbol{X}_{i s}\right) .
\end{aligned}
$$

This reinterpretation highlights that independence could be violated because either observable $\left(\overline{\boldsymbol{X}}_{g(i) s}\right)$ or unobservable $\left(\bar{u}_{g(i) s}\right)$ determinants of peer religiosity are not conditionally mean independent of the mental health residual, particularly $\eta_{g(i) s}$. We can test this in part by using peer characteristics $\overline{\boldsymbol{X}}_{g(i) s}$ that predict peer religiosity and are predetermined (i.e., age, mother has a college degree, mother not present, and father not present) as an alternative set of instruments, thus relaxing the assumption on $\bar{u}_{g(i) s}$. Column 1 of table 5 shows that estimates of the effect of religiosity are not statistically significantly different from the baseline results, though the instruments are weaker. ${ }^{29}$ Furthermore, these instruments pass the test of overidentifying restrictions, which would not hold if they were correlated with unobserved factors that affected depression.

We also directly test the role of observable peer characteristics by seeing whether they matter for mental health after instrumenting for religiosity. Column 2 presents the results when we control for peer characteristics. None of the peer characteristics are individually or jointly significant, and controlling for them does not change our estimates of the effect of religiosity. These results also control for peer depression, which could be an important additional omitted variable. We expect the coefficient on peer depression to be biased upward because of simultaneity, but we find that it is close to zero. Furthermore, estimates of the effect of religiosity remain robust at -0.62 . We find similar results if we control for either peer characteristics or peer depression in isolation. ${ }^{30}$ These results also

\footnotetext{
28 Note that if it is determined by peer religiosity, it is part of the social context of having peers who are more religious.

${ }^{29}$ Because the model is overidentified in this case, we use efficient two-step generalized method of moments for estimation.

${ }^{30}$ In unreported estimates, we also check that our results are not driven by school contextual variables that vary across grades and are used to define our subgroups, including the percentage female, the percentage belonging to different racial subgroups, and the percentage belonging to different denominations. None of these are individually or jointly significant in determining mental health. Most importantly, our estimated effect of religiosity on mental health is robust.
} 


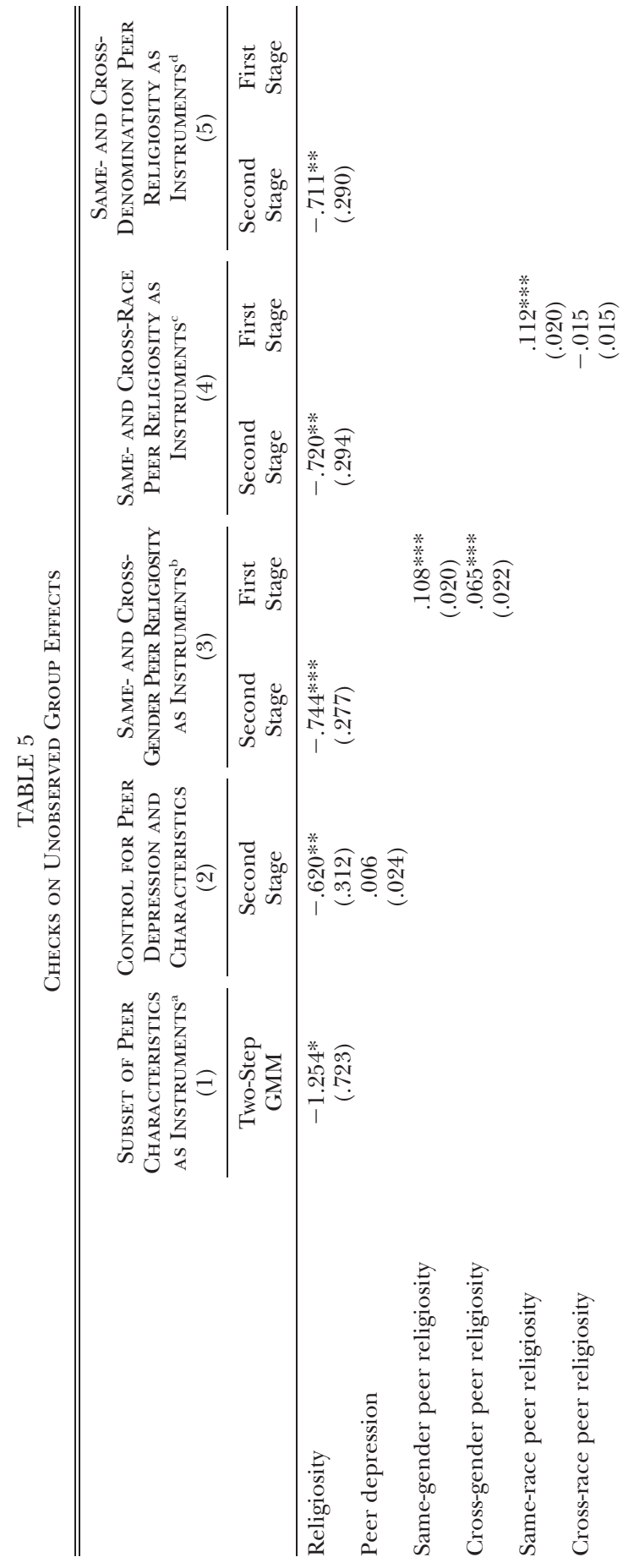

1196

This content downloaded from 130.209.115.082 on June 06, 2019 04:47:27 AM 


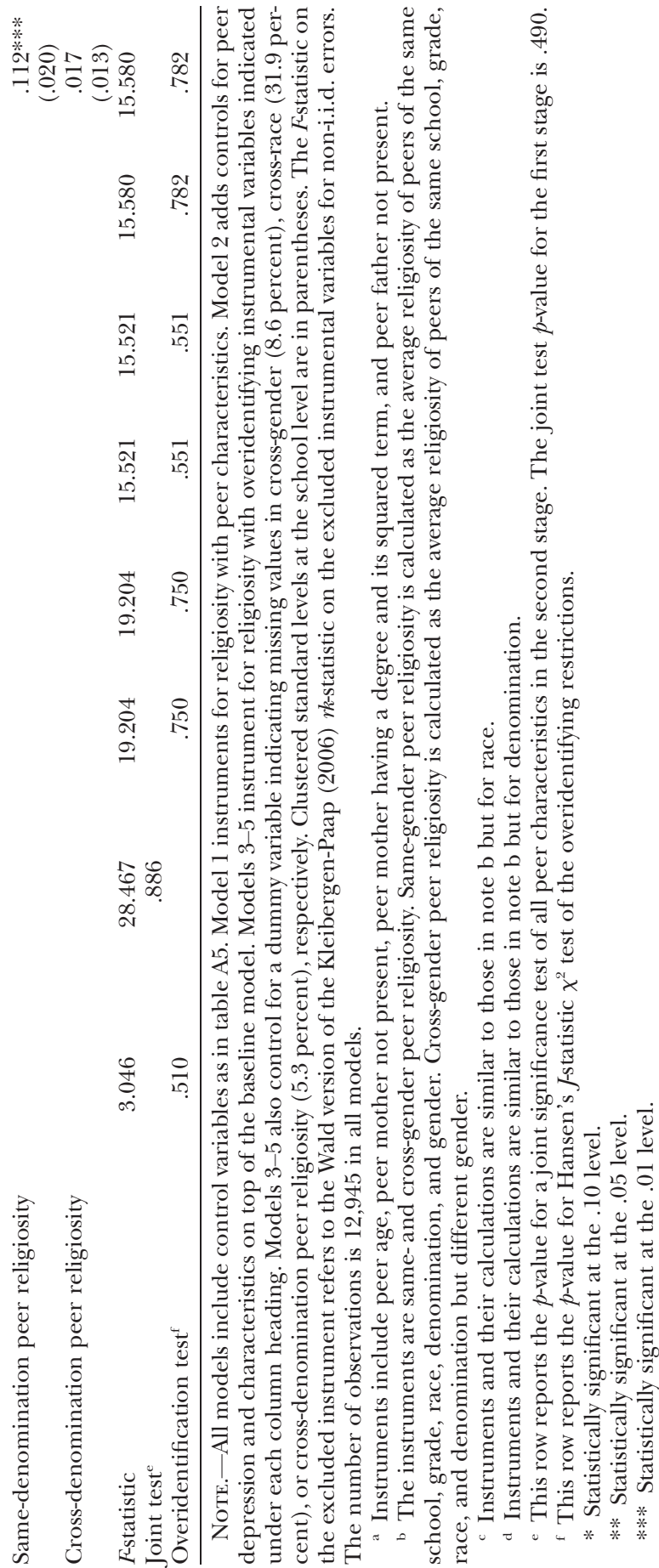

1197

This content downloaded from 130.209.115.082 on June 06, 2019 04:47:27 AM

All use subject to University of Chicago Press Terms and Conditions (http://www.journals.uchicago.edu/t-and-c). 
help to rule out an important additional concern that the findings are driven by reference group effects. We expect that if reference group effects at the peer group level were key determinants, then controlling for average peer depression would significantly affect our estimates of the effect of religiosity, which is not the case..$^{31}$

Because of the various ways in which we could define the relevant peer group, we also consider some overidentified cases (such as same- and crossgender peers of the same school-grade-race-denomination group) to see whether we pass the test of overidentifying restrictions as an additional test on certain types of unobserved group effects. For instance, if there were important unobserved group effects at the level of same schoolgrade-race-denomination, we would expect to fail the test of overidentifying restrictions using same- and cross-gender peers. The same logic can be applied to same- and cross-denomination and same- and cross-race peers. ${ }^{32}$ Column 3 shows that own religiosity is affected by both same-gender and cross-gender peers (of the same school, grade, race, and denomination), but relatively more by same-gender peers. Estimated effects of religiosity are robust, and we pass the test of overidentifying restrictions. In column 4, we consider the influence of same-race versus cross-race peers (of the same school, grade, gender, denomination), and in column 5, we consider the effects of same-and cross-denomination peers (of the same school, grade, gender, race). We find that neither cross-race nor cross-denomination peers affect religiosity. Most importantly, estimated effects of religiosity are similar across the different potential instrument sets, and we pass the test of overidentifying restrictions in all cases.

Finally, we provide further supportive evidence that the correlations of religiosity and depression are not driven by unobserved peer group-level factors by showing that noninstrumented estimated effects of religiosity on depression are similar whether we control for peer group fixed effects or not. Point estimates with peer group fixed effects are -0.14 (not reported) compared to -0.15 without (not reported), and a Hausman test supports that they are not statistically significantly different. ${ }^{33}$

${ }^{31}$ In results not reported, we find further that our estimates are robust to controlling for potential reference effects at all levels of potential references groups, including the schoolgrade, school-race, school-gender, school-denomination, school-grade-race, school-gradegender, school-grade-denomination, school-race-gender, school-race-denomination, and school-grade-race-gender average depression.

${ }^{32}$ This also helps with concerns about whether mismeasurement of peer groups could be biasing our estimated effects of religiosity, through correlation with peer religiosity and the residual from the depression equation.

${ }^{33}$ Recall from the discussion of table 1 that this was also true for the comparison of OLS to school fixed-effects results. Note that we cannot control for peer group fixed effects and use peer group religiosity as an instrument as there is not enough variation in the data. 


\section{Other Concerns}

Combined, these results provide support that our estimated effects of religiosity are not driven by selection or unobserved group effects. Further robustness tests described in appendix A.3 show that our results are robust to a number of other important concerns. We show robustness to scale concerns, removing possible social components of our depression measure and testing sensitivity to using polychoric correlations rather than simple aggregates. We also show robustness to a number of sample selection concerns, including dropping the nonreligious and non-Christians from the sample, along with those with missing peer groups. We also verify that our results are not driven by some unusual sampling features, such as measurement error in peer religiosity resulting from the selection of the in-home sample, the size of the school, and the number of peer groups.

\section{Mechanisms}

The primary hypothesis we are interested in testing is whether religiosity has a direct effect on mental health or if our estimated effect is driven by being in a more religious group of peers. This provides evidence on a key potential mechanism for how religiosity affects mental health that is highlighted in the literature-social support (Ellison and Henderson 2011). We then turn to other key mechanisms, whether religiosity reduces exposure to some types of stressors or buffers against these stressors. Finally, we consider whether there is evidence that the direct effects of religiosity on mental health operate through improved self-esteem and problem solving, key psychological resources and coping skills that have been identified in the literature as helpful for dealing with stress (Smith, Weigert, and Thomas 1979; Sherkat and Reed 1992).

\section{A. Social Context}

Because we rely on variation in peer group religiosity, we must be open to the interpretation of our estimated effect of religiosity as being inclusive of peer religiosity. As far as we know, this is a characteristic that is shared by all the instrumenting strategies used to identify the effect of religiosity; it is just made more explicit in our context. While the effect of religiosity inclusive of social context is arguably also of policy interest, we have a strong theoretical justification for why peers (as we have defined them) would not directly affect depression. Theoretical and applied literature in psychology suggests that peers affect depression primarily through close relationships and not through the typical status-oriented processes that we often consider in peer effects models, such as for externalizing behaviors (Brechwald and Prinstein 2011). For instance, Rose (2002) describes 
a process of co-rumination by which negative affect and hence depression spread among close friends, through dwelling on and reinforcing each other's negative experiences. Consistent with this, any evidence of contagion in depression in the literature is among friends and spouses (Stevens and Prinstein 2005; Prinstein 2007; van Zalk et al. 2010).

Because we observe friends in our data, we can test directly the hypothesis that depression spreads among close friends rather than the schoolcohort peer groups we have defined. We measure friends' depression as the average depression of any person whom $i$ nominates to be her friend. ${ }^{34}$ In column 1 of table 6 , we estimate the effects of religiosity controlling for average friends' depression. While we find that friends' depression matters, the estimated effects of religiosity are remarkably similar, which would not be the case if the effects of religiosity were driven by friends. ${ }^{35}$ That said, these are biased estimates of the effect of friends' depression because of measurement error and/or selection into friendship. In column 2, we address this by instrumenting for average friends' depression with sameschool-grade-race-gender peers' average depression. ${ }^{36}$ We find that though the estimated effects of friends' depression are larger after instrumenting, the effects of religiosity remain remarkably robust and, if anything, are higher. In column 3, we perform the same regression except controlling for friends' average religiosity in the first and second stages. In this case, average friends' religiosity is not statistically significantly correlated with depression, and estimated effects of religiosity are again similar. ${ }^{37}$ These combined results highlight the main reason that we believe we have identified an individual effect of religiosity rather than a social effect: the peer group as we have defined it matters for religiosity but not for depression, because contagion in depression occurs only among close friends.

A further test relies on the idea that if estimated effects are driven by social influence, we would expect the effect to be larger with more peers. Thus, columns 4 and 5 interact religiosity with the number of peers of the same school-grade-race-gender-denomination and the number of peers of the same denomination in the school. Formally, these regressions take the form

\footnotetext{
${ }^{34}$ As in table 2, we set average friends' depression to zero for the missing observations and include an indicator that the person is missing friends' depression. We also allow for the effect of religiosity to differ by whether the person is missing friendships.

${ }^{35}$ We also find that estimates of the effect of religiosity are not significantly different for the sample that is missing friends, which would not be the case if friends mattered.

${ }^{36}$ We choose average school-grade-race-gender peers' depression because this is a stronger predictor and gives better $F$-statistics than the same-school-grade-race-genderdenomination peers. It also fits observed patterns of friendship homophily.

${ }^{37}$ In unreported results, we also find that friends' characteristics are statistically significant predictors of religiosity and depression, which offers an interesting contrast to our findings on peer characteristics in table 5 and further corroborates our hypothesis. Estimates on religiosity are very similar when we control for peer and/or friend characteristics.
} 
TABLE 6

Individual and Social Effects of Religiosity on Depression

\begin{tabular}{|c|c|c|c|c|c|}
\hline & $\begin{array}{l}\text { Control for } \\
\text { Friends' } \\
\text { Depression } \\
\text { (1) }\end{array}$ & $\begin{array}{c}\text { Instrument for } \\
\text { Friends' } \\
\text { Depression } \\
\text { (2) }\end{array}$ & $\begin{array}{l}\text { Control for } \\
\text { Friends' } \\
\text { Religiosity } \\
\text { (3) }\end{array}$ & $\begin{array}{c}\text { Interact } \\
\text { Religiosity } \\
\text { with Peer } \\
\text { Group Size } \\
\quad(4)\end{array}$ & $\begin{array}{c}\text { Interact } \\
\text { Religiosity with } \\
\text { Number of } \\
\text { School- } \\
\text { Denomination } \\
\text { Students } \\
\text { (5) }\end{array}$ \\
\hline Religiosity & $\begin{array}{c}-.737 * * \\
(.307)\end{array}$ & $\begin{array}{c}-.856^{* * * *} \\
(.294)\end{array}$ & $\begin{array}{c}-.788 * * \\
(.385)\end{array}$ & $\begin{array}{c}-.752 * * \\
(.309)\end{array}$ & $\begin{array}{c}-.665^{* * *} \\
(.311)\end{array}$ \\
\hline Friends' depression & $\begin{array}{l}.076^{* * * *} \\
(.026)\end{array}$ & $\begin{array}{l}.172 * * \\
(.086)\end{array}$ & & & \\
\hline Friends' religiosity & & & $\begin{array}{l}.068 \\
(.072)\end{array}$ & & \\
\hline Religiosity $\times$ & & & & & \\
\hline friends missing & $\begin{array}{c}.046 \\
(.133)\end{array}$ & $\begin{array}{c}.058 \\
(.139)\end{array}$ & $\begin{array}{c}.093 \\
(.186)\end{array}$ & & \\
\hline Friends missing & $\begin{array}{c}.662 \\
(1.255)\end{array}$ & $\begin{array}{c}1.601 \\
(1.566)\end{array}$ & $\begin{array}{l}-.077 \\
(1.221)\end{array}$ & & \\
\hline $\begin{array}{l}\text { Religiosity } \times \text { peer } \\
\text { group size }\end{array}$ & & & & $\begin{array}{c}.008 \\
(.008)\end{array}$ & \\
\hline Peer group size & & & & $\begin{array}{c}-.064 \\
(.066)\end{array}$ & \\
\hline $\begin{array}{l}\text { Religiosity } \times \text { num- } \\
\text { ber of school- } \\
\text { denomination } \\
\text { students }\end{array}$ & & & & & $\begin{array}{c}-.000 \\
(.001)\end{array}$ \\
\hline $\begin{array}{l}\text { Number of school- } \\
\text { denomination } \\
\text { students }\end{array}$ & & & & & $\begin{array}{c}.002 \\
(.006)\end{array}$ \\
\hline$F$-statistic & 14.707 & 8.215 & 11.006 & 15.301 & 15.256 \\
\hline
\end{tabular}

Note.-All models include the covariates as in table A5. To allow for differential effects for those who have no valid friends data (65 percent), models $1-3$ include a binary indicator of friends missing and appropriate interaction terms described as below. Model 1 controls for friends' depression and the friends missing indicator on top of the baseline model, and instruments for religiosity and its interaction with friends missing, with peer religiosity and its interaction with friends missing. Model 2 further treats friends' depression as endogenous and instruments for it, with average depression of school-grade-race-gender peers and its interaction with friends missing. Model 3 controls for friends' religiosity as well as the friends missing indicator on top of the baseline model, and instruments for religiosity and its interaction with friends missing, with peer religiosity and its interaction with friends missing. Model 4 (or 5) instruments for religiosity and its interaction with peer group size (or the number of same-denomination students in the school) with peer religiosity and its interaction with peer group size (or the number of same-denomination students in the school), while controlling for peer group size (or the number of same-denomination students in the school). Peer group size refers to the number of peers in the same school-grade-racegender-denomination group. Clustered standard errors at the school level are in parentheses. The $F$-statistic on the excluded instrument refers to the Wald version of the KleibergenPaap (2006) $r k$-statistic on the excluded instrumental variables for non-i.i.d. errors. The number of observations is 12,945 in all models.

* Statistically significant at the .10 level.

** Statistically significant at the .05 level.

*** Statistically significant at the .01 level. 


$$
H_{i s}=\alpha_{1} R_{i s}+\boldsymbol{X}_{i s}^{\prime} \boldsymbol{\alpha}_{2}+\alpha_{3} R_{i s} W_{i s}+\alpha_{4} W_{i s}+\alpha_{s}+\varepsilon_{i s},
$$

where $W_{i s}$ denotes the relevant peer group size, $R_{i s}$ is instrumented by $\bar{R}_{g(i) s}$ as before, and $R_{i s} W_{i s}$ is instrumented by $\bar{R}_{g(i) s} W_{i s}{ }^{38}$ We do not find evidence that effects vary on the basis of the size of the peer group or the number of peers in the school of the same denomination. ${ }^{39}$

A related hypothesis is that if the effect of religion is driven through social support at school, we might expect other school activities (clubs or sports) to act as alternative social support structures, substituting for religiosity. In table 7, we consider whether there is evidence of substitutability, in that more religious students participate less in school activities. Columns 1-3 of panel A suggest that this is not the case. We also test whether religiosity matters less if the adolescent participates in school clubs or sports, following the model presented in equation (3), where $W_{i s}$ is now the number of clubs or sports or combined school activities. Columns 1-3 of panel B show that religiosity does not matter statistically significantly less for adolescents participating in school activities. This is true even though school activities are statistically significantly negatively correlated with depression. ${ }^{40}$ Finally, column 4 in both panels considers whether school friendships (measured by the in-degree, i.e., the number of schoolmates that nominate a given adolescent as a friend) substitute for religiosity. Again, we find that religiosity does not significantly affect school friendships and does not seem to matter less for individuals with more friends. Thus, the evidence does not support that school activities or friendships offer substitute support structures for religiosity in their effects on depression.

\section{B. Stressors}

The literature suggests that religiosity reduces exposure to stressors that may be correlated with mental health (Ellison and Henderson 2011). We present in table 8 evidence on this, selecting a set of stressors selected on

${ }^{38}$ Note that this is easiest to interpret when $W_{i s}$ is exogenous, which may not be plausible here. Bun and Harrison (2014) describe conditions under which the interaction can be interpreted as exogenous even if $W_{i s}$ is endogenous. In our context some reasonable sufficient conditions are that the covariance of $W_{i s}$ and the unobservable determinants of mental health do not vary systematically with peer religiosity and that peer religiosity is independent of $W_{i s}$ or is a linear function of $W_{i s}$.

${ }^{39}$ A number of other specifications (not reported) such as the percentage in the grade or percentage of the same denomination in the county similarly show no statistically significant interactions with religiosity.

${ }^{40}$ We test robustness of these findings to a variety of functional form assumptions, such as allowing both the decision to participate in sports and the number of sports to matter, as well as considering the log of the number of sports to deal with the skewed distribution. We also test sensitivity to outliers. In no case can we find evidence that these activities substitute for religiosity. 
TABLE 7

Religiosity, School Activities, And Depression

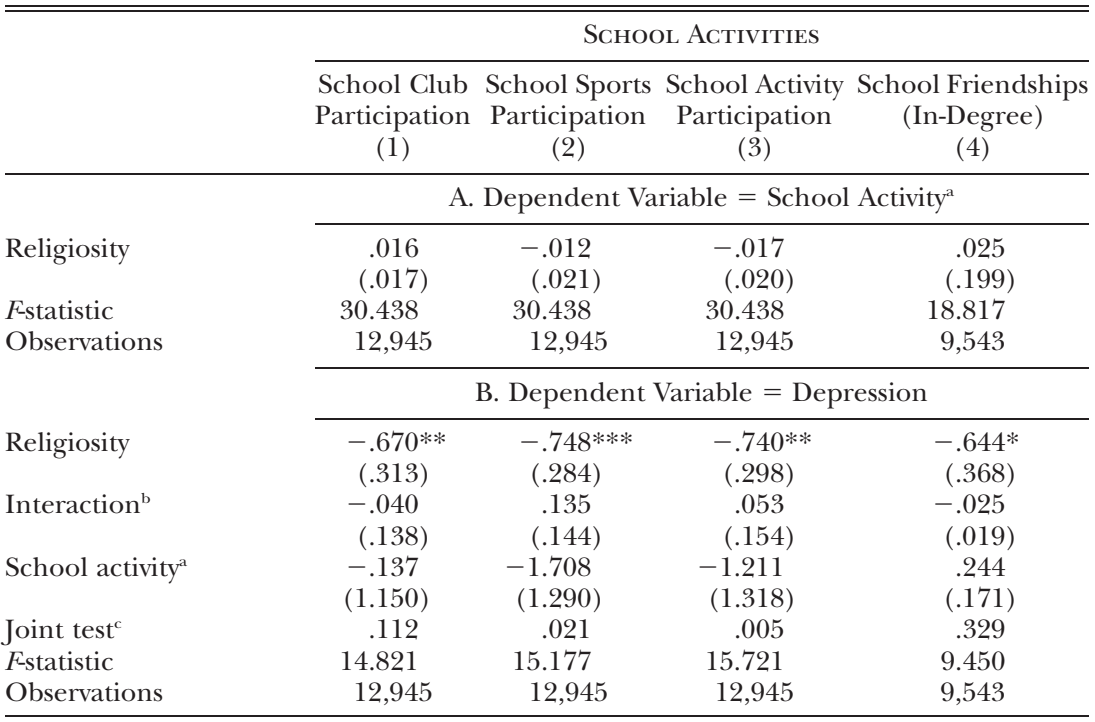

NoTE.-Panel A reports the IV estimates for the effect of religiosity on school activities. Panel B reports the IV estimates for the main and interaction effect of religiosity on depression conditional on school activities. All models control for covariates as in table A5. Clustered standard errors at the school level are in parentheses. The $F$-statistic refers to the Wald version of the Kleibergen-Paap (2006) $r k$-statistic on the excluded instrumental variables for non-i.i.d. errors.

a Each school activity refers to the one indicated in the column heading. Detailed definition for school activities can be found in table A1.

$\mathrm{b}$ This is the interaction term between religiosity and school activities.

c This reports the $p$-value of a joint significance test of school activity and its interaction term with religiosity.

* Statistically significant at the .10 level.

** Statistically significant at the .05 level.

*** Statistically significant at the .01 level.

the basis of whether we find them to be correlated with depression: grade point average (GPA), whether a family member or friend has committed suicide in the past 12 months, general health, and whether the adolescent is in a single-parent family. ${ }^{41}$ Panel A shows the instrumented effects of religiosity on each of these stressors. Religiosity does not reduce exposure to these types of stressors in statistically significant ways. Panel B then considers whether there is evidence of stress-buffering effects of religiosity, using the same model as in equation (3), where $W_{\text {is }}$ is now defined as a different stressor of interest in each column. We find that the stress-

\footnotetext{
${ }^{41}$ We also consider parental divorce, whether the parents fight, or whether parents have other marriage difficulties or financial problems, but these are not significantly related to depression conditional on covariates.
} 
TABLE 8

Stress-Buffering EfFects of Religiosity on Depression

\begin{tabular}{|c|c|c|c|c|}
\hline & \multicolumn{4}{|c|}{ STRESSOR } \\
\hline & $\begin{array}{c}\text { Most } \\
\text { Recent GPA } \\
(1)\end{array}$ & $\begin{array}{c}\text { Family or } \\
\text { Friends Suicide } \\
(2)\end{array}$ & $\begin{array}{l}\text { General } \\
\text { Health } \\
(3)\end{array}$ & $\begin{array}{l}\text { Single } \\
\text { Parent } \\
\quad(4)\end{array}$ \\
\hline & \multicolumn{4}{|c|}{ A. Dependent Variable $=$ Stressor $^{\mathrm{a}}$} \\
\hline Religiosity & $\begin{array}{c}.033 \\
(.031)\end{array}$ & $\begin{array}{c}-.006 \\
(.019)\end{array}$ & $\begin{array}{c}-.063 \\
(.039)\end{array}$ & $\begin{array}{c}.014 \\
(.013)\end{array}$ \\
\hline$F$-statistic & 30.425 & 30.284 & 30.416 & 28.102 \\
\hline \multirow[t]{2}{*}{ Observations } & 12,838 & 12,888 & 12,944 & 10,504 \\
\hline & \multicolumn{4}{|c|}{ B. Dependent Variable $=$ Depression } \\
\hline Religiosity & $\begin{array}{c}-.667 * \\
(.349)\end{array}$ & $\begin{array}{c}-.643 * * \\
(.293)\end{array}$ & $\begin{array}{c}-1.436^{* * * *} \\
(.389)\end{array}$ & $\begin{array}{r}-.575^{*} \\
(.320)\end{array}$ \\
\hline Interaction $^{\mathrm{b}}$ & $\begin{array}{c}.015 \\
(.088)\end{array}$ & $\begin{array}{l}-.598 * * * \\
(.197)\end{array}$ & $\begin{array}{l}.160 * * \\
(.072)\end{array}$ & $\begin{array}{r}-.322^{*} \\
(.177)\end{array}$ \\
\hline Stressor ${ }^{\mathrm{a}}$ & $\begin{array}{c}-1.747 * * \\
(.780)\end{array}$ & $\begin{array}{l}8.214^{* * * *} \\
(1.687)\end{array}$ & $\begin{array}{c}-3.050 * * * \\
(.623)\end{array}$ & $\begin{array}{r}2.630^{*} \\
(1.525)\end{array}$ \\
\hline$F$-statistic & 14.615 & 14.914 & 16.010 & 14.120 \\
\hline Observations & 12,838 & 12,888 & 12,944 & 10,504 \\
\hline
\end{tabular}

Note.-Panel A reports the IV estimates for the effect of religiosity on exposure to stressors. Panel B reports the IV estimates for the main and interaction effect of religiosity on depression conditional on stressors. All models control for covariates as in table A5. Clustered standard errors at the school level are in parentheses. The $F$-statistic refers to the Wald version of the Kleibergen-Paap (2006) $r k$-statistic on the excluded instrumental variables for non-i.i.d. errors.

a Each stressor refers to the one indicated in the column heading. Detailed definition for stressors can be found in table Al.

b This is the interaction term between religiosity and stressor.

* Statistically significant at the .10 level.

** Statistically significant at the .05 level.

*** Statistically significant at the .01 level.

buffering hypothesis does seem to hold for the suicide of someone close to the adolescent, general health, and coming from a single-parent family, but not for GPA.

\section{Self-Esteem and Passive Problem Solving}

Psychologists hypothesize that religiosity can support mental health through self-esteem if, for instance, a relationship with the divine helps provide a sense of worth. ${ }^{42}$ A second related theory is that religiosity affects mental health through how people cope with difficult situations or problems, by inspiring a more fatalistic perspective on life, leading one to engage in more passive problem-solving attitudes (Pargament and Brant 1998).

\footnotetext{
${ }^{42}$ Importantly, the arguments for why religiosity could support self-esteem could also be turned to suggest reasons why religiosity could hurt self-esteem (Ellison and Henderson 2011).
} 
Add Health includes questions that are intended to reflect the adolescent's self-esteem and approaches to problem solving, and we create an index of self-esteem and passive problem solving based on these questions. ${ }^{43}$ Table A11 considers the effect of religiosity on self-esteem and passive problem solving. Consistent with the literature described in Ellison and Henderson (2011), OLS shows that religiosity is positively correlated with self-esteem. When we instrument for religiosity, the estimated effect of religiosity increases from 0.075 to 0.15 in the case of self-esteem and from 0.02 to 0.11 for the case of passive problem solving. However, the standard errors are also large so that our IV results are not statistically significantly different from zero. This does not provide strong support that self-esteem and passive problem solving are key channels for the effect of religiosity, at best suggesting a degree of heterogeneity in the effects of religiosity on these potential mediators. ${ }^{44}$

\section{Conclusion}

In this paper, we find that a one-unit increase in religiosity decreases the probability of being depressed by 3 percent out of a probability of 24 percent. To put this estimate in context, an increase in mother's education from no high school diploma to a high school diploma or more is correlated with only a 5 percent reduction in the probability of being depressed. Our estimated effect of religiosity is bigger than what is found in OLS. This could be a result of negative selection into religiosity, that is, that individuals may select into religiosity to deal with depression or shocks associated with depression, as evidenced in the literature, or because of random measurement error in individuals' reported religiosity.

Interestingly, while the effects of religiosity on depression do not vary by how religious the individual is, more depressed individuals benefit significantly more from religiosity than the least depressed. This offers a striking contrast to evidence on the effectiveness of cognitive-based therapy, one of the most recommended forms of treatment, which is generally less effective for the most depressed individuals.

The method we use to identify a causal effect of religiosity relies on variation in peer composition within schools across time. Our results are robust to a large number of specification checks, helping us rule out potential confounders such as selection into peer groups and unobservable

\footnotetext{
${ }^{43}$ See details in table Al and discussion of these measures in Rosenberg (1989) and Nooney (2005).

${ }_{44}$ Table A11 further shows evidence of a mediating effect of self-esteem and passive problem solving in that the coefficient of religiosity on depression is statistically significantly reduced when these are controlled for. That said, the evidence is not conclusive given the strong possibility of reverse causality from depression to self-esteem and passive problem solving.
} 
shocks that affect the group as a whole. We show that the reason the crosscohort peer variation identifies an individual effect of religiosity rather than a social effect is that the peers that matter for depression appear to be different from the peers that matter for religiosity, which is consistent with theory and previous studies on depression. We find that school peers of the same denomination, regardless of whether they are friends, have a particularly strong association with adolescents' religiosity, whereas close friends are highly associated with mental health. While there is significant discussion of the complex nature of adolescent peer groups in the psychology literature (Brown 2004), less is known about different realms of influence for peer groups in different aspects of adolescents' lives (Brechwald and Prinstein 2011). We see this as an important avenue for further research in economics.

We consider potential mechanisms for why religiosity may affect depression. We show that the benefits of religiosity do not appear to derive from a more religious or less depressed social context in the school. Furthermore, alternative forms of school social support, such as clubs, sports, and the number of friends, do not appear to substitute for religiosity. We also do not find evidence that religiosity reduces exposure to stressors. We find instead that religiosity helps to buffer against some types of stressors, including poor health, the suicide of a friend or family member, or coming from a single-parent home. We find that while the hypothesis of religiosity operating through improved self-esteem and coping skills is supported by OLS, our instrumented estimates show larger but statistically insignificant effects of religiosity on these potential mediators, raising questions about their role.

Overall, our findings have important implications for policies related to improving mental health in adolescence. Given that clinically the effect of antidepressants on reducing depression is successful in about onefifth of cases (Informed Health Network 2015), our research suggests that counselors would be remiss to dismiss the potential beneficial effect of religiosity in treating clients, contributing to a vigorous debate initiated by Freud (1927). Future work would benefit from more detailed information on churches and other places of worship that adolescents attend to determine further the mechanisms driving these effects.

\section{References}

Agency for Healthcare Research and Quality. 2014. "Mental Health: Research Findings." http://www.ahrq.gov/.

Baum, Christopher F., Mark E. Schaffer, and Steven Stillman. 2002. "IVREG2: Stata Module for Extended Instrumental Variables/2SLS and GMM Estimation." Statistical software components, Dept. Econ., Boston Coll. http://ideas .repec.org/c/boc/bocode/s425401.html. 
Becker, Sascha O., and Ludger Woessmann. 2011. "Knocking on Heaven's Door? Protestantism and Suicide.” IZA Discussion Paper no. 5773, Inst. Study Labor, Bonn.

Brechwald, Whitney A., and Mitchell J. Prinstein. 2011. "Beyond Homophily: A Decade of Advances in Understanding Peer Influence Processes." I. Res. Adolescence 21 (1): 166-79.

Brown, B. Bradford. 2004. “Adolescents' Relationships with Peers.” In Handbook of Adolescent Psychology, 2nd ed., edited by Richard M. Lerner and Laurence Steinberg, chap. 12. Hoboken, NJ: Wiley.

Bun, Maurice J. G., and Teresa D. Harrison. 2014. "OLS and IV Estimation of Regression Models Including Endogenous Interaction Terms." Working Paper no. 2014-3, School Econ., LeBow Coll. Bus., Drexel Univ.

Center for Behavioral Health Statistics and Quality. 2016. "Key Substance Use and Mental Health Indicators in the United States: Results from the $2015 \mathrm{Na}$ tional Survey on Drug Use and Health.” Report no. SMA 16-4984, Center Behavioral Health Statis. and Quality, Washington, DC. https://www.samhsa .gov/.

Cheadle, Jacob E., and Philip Schwadel. 2012. "The 'Friendship Dynamics of Religion,' or the 'Religious Dynamics of Friendship'? A Social Network Analysis of Adolescents Who Attend Small Schools.” Soc. Sci. Res. 41 (5): 1198-1212.

Child Trends Databank. 2014a. "Attendance at Religious Services." https://bit .ly/2voEUBE.

- 2014b. "Religiosity among Youth." https://bit.ly/2LbzlkO.

Chiswick, Barry R., and Donka M. Mirtcheva. 2013. "Religion and Child Health: Religious Affiliation, Importance, and Attendance and Health Status among American Youth." J. Family and Econ. Issues 34 (1): 120-40.

Cook, Mary N., John Peterson, and Christopher Sheldon. 2009. "Adolescent Depression: An Update and Guide to Clinical Decision Making." Psychiatry 6 (9): $17-31$.

Crabtree, Steve. 2010. "Religiosity Highest in World's Poorest Nations." Report, Gallup. http://www.gallup.com/.

Cunha, Flavio, and James J. Heckman. 2008. "Formulating, Identifying and Estimating the Technology of Cognitive and Noncognitive Skill Formations." J. Human Resources 43 (4): 738-82.

Cunha, Flavio, James J. Heckman, and Susanne M. Schennach. 2010. "Estimating the Technology of Cognitive and Noncognitive Skill Formation." Econometrica 78 (3): 883-931.

Desmond, Scott A., Kristopher H. Morgan, and George Kikuchi. 2010. "Religious Development: How (and Why) Does Religiosity Change from Adolescence to Young Adulthood?" Sociological Persbectives 53 (2): 247-70.

Ellison, Christopher G., Jason D. Boardman, David R. Williams, and James S. Jackson. 2001. "Religious Involvement, Stress, and Mental Health: Findings from the 1995 Detroit Area Study." Soc. Forces 80 (1): 215-49.

Ellison, Christopher G., and Andrea K. Henderson. 2011. "Religion and Mental Health: Through the Lens of the Stress Process." In Toward a Sociological Theory of Religion and Health, edited by Anthony J. Blasi, 11-44. Leiden, Neth.: Brill.

Ferraro, Kenneth F., and Jessica A. Kelley-Moore. 2000. "Religious Consolation among Men and Women: Do Health Problems Spur Seeking?” L. Scientific Studv Religion 39 (2): 220-34.

Freud, Sigmund. 1927. The Future of an Illusion. Translated by W. D. Robson-Scott. Garden City, NY: Doubleday. 
Gloaguen, Valerie, Jean Cottraux, Michel Cucherat, and Ivy-Marie Blackburn. 1998. "A Meta-Analysis of the Effects of Cognitive Therapy in Depressed Patients." I. Affective Disorders 49 (1): 59-72.

Gruber, Jonathan H. 2005. "Religious Market Structure, Religious Participation, and Outcomes: Is Religion Good for You?” Advances Econ. Analysis and Policy 5 (1): art. 5.

Gruber, Jonathan H., and Daniel M. Hungerman. 2008. "The Church versus the Mall: What Happens When Religion Faces Increased Secular Competition?" O.J.E. 123 (2): 831-62.

Hackney, Charles H., and Glenn S. Sanders. 2003. "Religiosity and Mental Health: A Meta-Analysis of Recent Studies." I. Scientific Studv Relioion 42 (1): 43-55.

Heckman, James J., Jora Stixrud, and Sergio Urzua. 2006. "The Effects of Cognitive and Noncognitive Abilities on Labor Market Outcomes and Social Behavior." L. Labor Econ. 24 (3): 411-82.

Hungerman, Daniel M. 2011. "Rethinking the Study of Religious Markets." In The Oxford Handbook of the Economics of Religion, edited by Rachel M. McCleary. Oxford: Oxford Univ. Press.

Iannaccone, Laurence R. 1998. "Introduction to the Economics of Religion." J. Econ. Literature 36 (3): 1465-95.

Informed Health Network. 2015. "Depression: How Effective Are Antidepressants?" Technical report, Inst. Quality and Efficiency in Health Care, Cologne, Ger.

Iyer, Sriya. 2016. “The New Economics of Religion.” LEcon. Literature 54 (2): 395441.

Kleibergen, Frank, and Richard Paap. 2006. "Generalized Reduced Rank Tests Using the Singular Value Decomposition." I. Econometrics 133 (1): 97-126.

Langa, Kenneth M., Marcia A. Valenstein, A. Mark Fendrick, Mohammed U. Kabeto, and Sandeep Vijan. 2004. "Extent and Cost of Informal Caregiving for Older Americans with Symptoms of Depression." American I. Psychology 161:857-63.

Levin, Jeff. 2010. "Religion and Mental Health: Theory and Research." Internat.J. Appl. Psychoanalytic Studies 7 (2): 102-15.

Manski, Charles. 1993. "Identification of Endogenous Social Effects: The Reflection Problem." Rev. Econ. Studies 60 (3): 531-42.

March, John S., Susan Silva, Stephen Petrycki, et al. 2007. "The Treatment for Adolescents with Depression Study (TADS): Long-Term Effectiveness and Safety Outcomes." Archives General Psvchiatry 64 (10): 1132-43.

McPherson, Miller, Lynn Smith-Lovin, and James M. Cook. 2001. "Birds of a Feather: Homophily in Social Networks." Ann. Rev. Sociology 27:415-44.

Mellor, Jennifer M., and Beth A. Freeborn. 2011. "Religious Participation and Risky Health Behaviors among Adolescents." Health Econ. 20 (10): 1226-40.

Newport, Frank. 2014. "Majority Still Says Religion Can Answer Today's Problems.” Report, Gallup. http://www.gallup.com/.

Nooney, Jennifer G. 2005. "Religion, Stress, and Mental Health in Adolescence: Findings from Add Health." Rev. Religious Res. 46 (4): 341-54.

Pargament, Kenneth I., and Curtis R. Brant. 1998. "Religion and Coping." In Handbook of Religion and Mental Health, edited by Harold G. Koenig. San Diego: Academic Press.

PewForum. 2012. “The Global Religious Landscape.” Report, Forum on Religion and Public Life, Pew Res. Center, Washington, DC. http://www.pewforum .org/. 
Prinstein, Mitchell J. 2007. "Moderators of Peer Contagion: A Longitudinal Examination of Depression Socialization between Adolescents and Their Best Friends." L. Clinical Child and Adolescent Psychology 36 (2): 159-70.

Radloff, Lenore S. 1977. "The CES-D Scale: A Self-Report Depression Scale for Research in the General Population." Appl. Psychological Measurement 1 (3): 385401.

Rose, Amanda J. 2002. "Co-rumination in the Friendships of Girls and Boys." Child Develobment 73 (6): 1830-43.

Rosenberg, Morris. 1989. Society and the Adolescent Self-Image. Rev. ed. Middletown, CT: Wesleyan Univ. Press.

Sherkat, Darren E., and Mark D. Reed. 1992. "The Effects of Religion and Social Support on Self-Esteem and Depression among the Suddenly Bereaved." Soc. Indicators Res. 26 (3): 259-75.

Smith, Christian, and Melinda Lundquist Denton. 2005. Soul Searching: The Religious and Spiritual Lives of American Teenagers. Oxford: Oxford Univ. Press.

Smith, Christopher B., Andrew J. Weigert, and Darwin L. Thomas. 1979. "SelfEsteem and Religiosity: An Analysis of Catholic Adolescents from Five Cultures." L. Scientific Studv Religion 18 (1): 51-60.

Stevens, Elizabeth A., and Mitchell J. Prinstein. 2005. "Peer Contagion of Depressogenic Attributional Styles among Adolescents: A Longitudinal Study." J. Abnormal Child Psychology 33:25-38.

van Zalk, Maarten H. W., Margaret Kerr, Susan J. T. Branje, Hakan Stattin, and Wim H. J. Meeus. 2010. "It Takes Three: Selection, Influence, and De-selection Processes of Depression in Adolescent Friendship Networks." Develpmental Psvchology 46 (4): 927-38.

WHO (World Health Organization). 2014. "Health for the World's Adolescents: A Second Chance in the Second Decade." Report, World Health Org., Geneva.

Williams, Paula G., Grayson N. Holmbeck, and Rachel N. Greenley. 2002. "Adolescent Health Psychology." L. Consulting and Clinical Psychology 70 (3): 828-42. 